\title{
Extreme High Temperature Hazard Assessment for Summer Corn at Henan Province
}

\author{
Qi Zhang ${ }^{1}$, Wenjie Huang ${ }^{2}$ \\ ${ }^{1}$ School of Applied Meteorology, Nanjing University of Information Science \& Technology, Nanjing \\ 210044, China \\ ${ }^{2}$ BijieMeteorological Administration of Guizhou Province, Bijie 553299, China

\section{河南夏玉米不同生育阶段极端高温灾害危险性 分析} \\ 张琪 ${ }^{1}$, 黄文杰 ${ }^{2}$ \\ ${ }^{1}$ 南京信息工程大学应用气象学院, 南京 210044 , 中国 \\ 2贵州省毕节市气象局, 毕节 553299 , 中国
}

\begin{abstract}
Extreme high temperature (EHT) brings great losses for agriculture under global warming. Based on "accumulate temperature and yield" model, threshold of EHT for corn were determined, and then to study the spatial and temporal characters of EHT and its effects on corn. The results shown that (1) the threshold of EHT in Henan were $37.19^{\circ} \mathrm{C}, 35.52^{\circ} \mathrm{C}$ and $36.74{ }^{\circ} \mathrm{C}$ for the growth periods of before summer corn jointing, after jointing and the whole growing season at Henan. (2) The frequency and intensity of EHT increased with time during 1981-2012, this trend was more obvious at before jointing stage. (3) EHT happened during after jointing stage would bring much more serious influence on corn yields.
\end{abstract}

Keywords:summer corn; extreme hightemperature; threshold; hazard

\section{摘要}

气候变化背景下极端高温灾害频发给 农业生产带来极大影响。本研究基于积温 产量模型方法确定河南省夏玉米不同生育 阶段高温阈值并对极端高温危险性和对产
量影响进行分析。研究结果表明:（1）河 南省夏玉米拔节前、后以及全生育期的极 端高温阈值分别为 $37.19{ }^{\circ} \mathrm{C}, 35.52^{\circ} \mathrm{C}$, $36.74^{\circ} \mathrm{C}$; (2) 1981-2012 年间极端高温灾 害的发生频率、强度均不断增强, 特别是 拔节前; (3) 夏玉米产量受拔节后的极端 高温影响最大。

关键词: 夏玉米; 极端高温; 阈值; 危险 性

\section{1. 引言}

全球变化背景下, 极端高温事件愈发 频繁, 尤其在 1995-2000 年期间, 我国北 部地区极端高温事件的发生率大幅度提升 ${ }^{[1]}$, 2010 年我国极端高温与极端降水事件发生 的强度与频率均为十九世纪六十年代以来 最强的一年, 并且据研究统计显示, 在接 下来的一段时间内, 中国的极端高温事件 频数将以明显的线性趋势不断增大 ${ }^{[2]}$ 。由极 端高温导致的气象灾害仅在 2000 年就使我 国超过 4054 万平方公顷的土地出现大范围 干旱, 其中成灾面积达 2678 万平方公顷, 为我国农业生产带来了不可估量的损失 ${ }^{[3]}$ 。 河南省是我国夏玉米、冬小麦的主产区 ${ }^{[4]}$, 高温灾害频发，给农民收入、国家粮食安 全带来极大的危险。急需针对农业高温灾 害开展研究。 
极端高温属于极端事件的一种, 是指 气温异常高于往期统计分布上限末端的数 值时的天气现象 ${ }^{[5]}$ 。极端事件阈值确定主要 分为绝对阈值法和百分比阈值法。绝对阈 值, 即使用绝对值作为极端事件临界值, 例如直接以 $35^{\circ} \mathrm{C} 、 38^{\circ} \mathrm{C} 、 40^{\circ} \mathrm{C}$ 等作为 阈值研究高温灾害的影响 ${ }^{[6]}$ 。百分比阈值, 一般以数据序列的第 99 或 95 百分位所对 应的温度临界值作为极端高温天气的阈值。 在研究极端事件的影响时, 阈值的确定往 往没有充分考虑承载体的特点, 因而影响 评估结果的合理性尚待考究。不同作物对 极端高温的敏感程度不同，即使同种作物 在不同生育阶段对极端高温的敏感程度也 不同, 例如在玉米的灌浆期发生高温更容 易造成产量损失 ${ }^{[7]}$ 。因而急需开展考虑承载 体特征的极端高温阈值确定的研究。

综上所述, 针对河南省夏玉米生产受 极端高温影响严重的这一问题, 本研究拟 采用 “积温-产量” 模型的方法确定河南省 夏玉米极端高温阈值, 并分析极端高温事 件时空分布特征及对夏玉米产量的影响。 为当地防灾减灾政策的制定, 指导夏玉米 生产提供依据。

\section{2. 资料与方法}

\section{1 数据来源}

本次研究使用的气象数据为河南省 10 个站点（图 1）所观测到的 1981-2012 年的
逐日最高和最低气温数据。资料来源于中 国气象数据网。作物资料包括 1981-2012 年各站点夏玉米播种、拔节、成熟日期, 以及产量数据。资料来源于中国气象局农 业气象观测站和河南省历年统计年鉴。夏 玉米在拔节前为营养生长, 拔节后开始进 行生殖生长, 本文拟将夏玉米生育期分为 播种至拔节和拔节至成熟两个阶段开展研 究。

\section{2 研究方法}

(1) 积温-产量模型

当研究气温对作物产量的影响时, 一 般认为温度对产量的影响是一个非线性的 累积过程, 产量与整个生育阶段有效积温 成比例关系。基于这一思想, 张琪等人对 Schlenker\& Roberts 在对美国主要粮食作 物受高温影响研究时构建的非线性模型进 行完善, 得到下面的非线性函数来模拟产 量与生育期温度之间的关系 ${ }^{[8-9]}$ 。

$$
y_{i j}=k \int_{T_{\min }}^{T_{\max }} g(T) \emptyset_{i j}(T) d T+\varepsilon
$$

式中 $g(T)$ 为不同温度 $T$ 对应的有效积 温; $\emptyset_{i j}(T)$ 为站点 $i$ 年 $j$ 玉米在生育期内不同 温度 $(T)$ 下持续时长 (小时); $T_{\text {max }} 、 T_{\text {min }}$ 分 别为生育期内温度的上、下限。 $\int_{T_{\text {min }}}^{T_{\text {max }}} g(T) \emptyset_{i t}(T) d T$ 描述了生育期的总有效 积温。进而, $k$ 可以作为有效积温转化为产

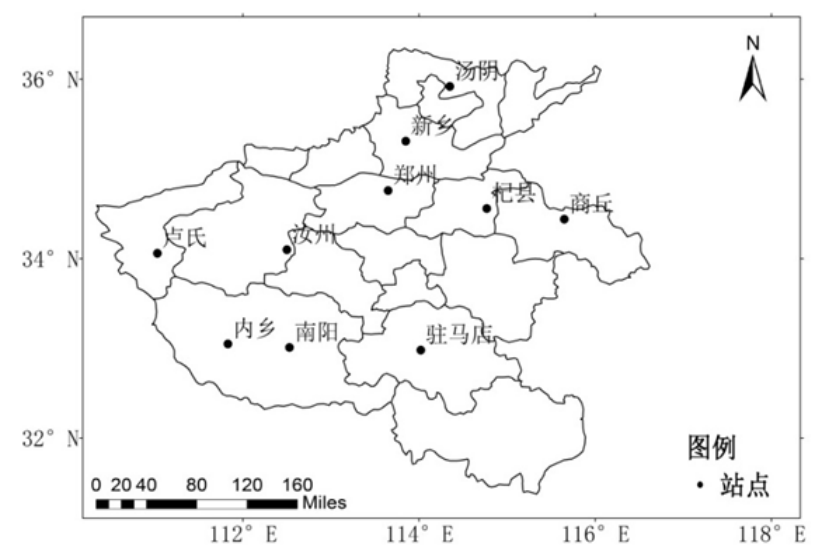

图 1. 研究区气象站点分布图 
量的系数, $k$ 越大则同样的有效积温转化成 的产量越多, 产量累积效率高。

本文以 $8^{\circ} \mathrm{C}$ 和 $32^{\circ} \mathrm{C}$ 作为玉米有效积温 的上下限, 即:

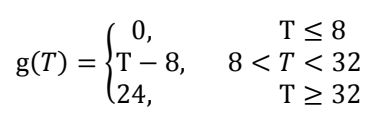

式中, $\mathrm{T}$ 为逐小时温度, $\mathrm{g}(\mathrm{T})$ 为该温度 贡献的有效积温。在以往的研究中采用该 方法得到的夏玉米极端高温阈值在 $35^{\circ} \mathrm{C}$ 附 近, 符合生产实际。

（2）极端高温事件频率、强度的计算 极端高温事件发生频率 $P$ 的计算公式有:

$$
\begin{gathered}
e d_{k}= \begin{cases}0 & T_{k} \leq t \\
1 & T_{k}>t\end{cases} \\
E D=\sum_{k=1}^{n} e d_{k} \\
P=\frac{E D}{n} \times 100 \%
\end{gathered}
$$

式中, $e d_{k}$ 为第 $k$ 天是否发生极端高温 事件的情况, 即发生极端高温, 记 $e d_{k}=1$, 否则为 $0 。 T_{k}$ 为第 $k$ 天日最高气温, $t$ 为不同 生育期内极端高温阈值, $E D$ 表示生育期内 出现的极端高温的日数, $n$ 为生育期总天数。 强度 $Q$ 计算公式如下:

$$
\begin{array}{r}
e t_{k}=\left\{\begin{array}{ll}
0 & T_{k} \leq t \\
\left(T_{k}-t\right) & T_{k}>t
\end{array}(6)\right. \\
E T=\sum_{k=1}^{n} e t_{k}(7) \\
Q=\frac{E T}{E D} \quad(8)
\end{array}
$$

式中, $e t_{k}$ 表示第 $k$ 天发生极端高温事件 时当日最高气温与阈值之间的差值, 若未 发生极端高温, 则 $e t_{k}$ 为 0 。 $E T$ 表示生育期 内极端高温日的日最高气温与阈值的温度 差之和。

\section{3. 结果与分析}

\section{1 河南省夏玉米不同生育阶段极端高温 阈值的确定}

根据积温-产量模型 (公式 1) 拟合各 站点各年不同生育阶段温度与当年实际产 量的积分函数图像 (图 2 中灰色曲线)。图 像中横坐标为温度, 纵坐标为该温度贡献 的产量, 曲线与横坐标所围得面积即为该 站点当年实际产量。黑色曲线为所有灰色
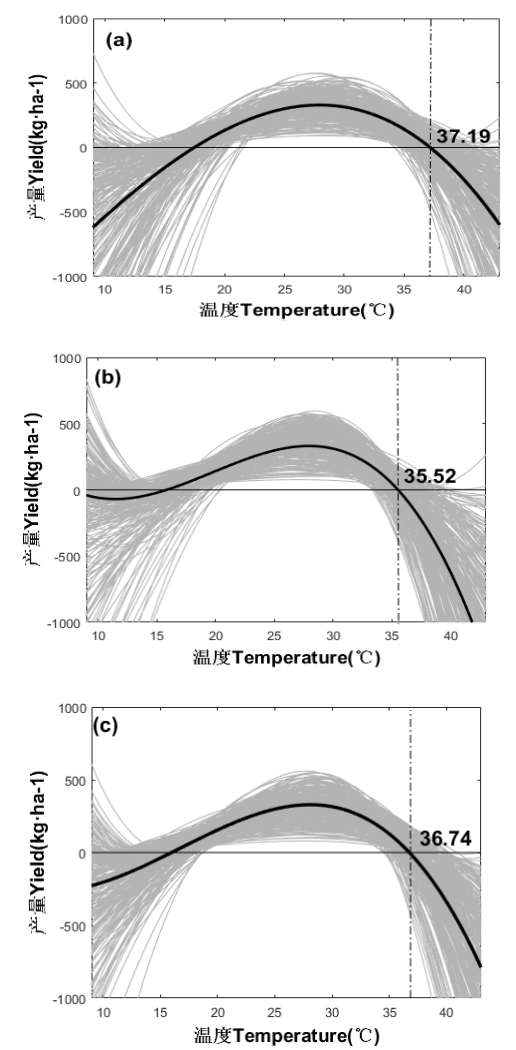

图 2. 不同阶段温度-产量积分函数图像 (a. 拔节前; b. 拔节后; c. 为全生育期)

曲线的平均。可以看出在, 随着温度的升 高其贡献的产量随之增加, 在 $28^{\circ} \mathrm{C}$ 左右达 到最大值。其后随着温度继续升高其贡献 的产量逐渐降低。在河南省夏玉米拔节前、 后及整个生育期分别在 $37.19^{\circ} \mathrm{C} 、 35.52^{\circ} \mathrm{C}$ 、 $36.74^{\circ} \mathrm{C}$ 时的积温转化成的产量为零, 超过 这一数值贡献的产量为负值, 说明温度对 夏玉米生产造成负面效应, 可定义为极端 高温事件的阈值。可以看出在拔节后阈值 较低, 说明这一阶段对高温的反应更为灵 敏。

\section{2 河南省夏玉米极端高温事件时空分布 特征}

(1) 极端高温事件发生频率的时空分 布

由图 3 可以看出在这三个阶段极端高 
温事件发生频率都有随时间增加的趋势, 其中尤以拔节前增长趋势最大最明显, 斜 率约为 0.19 , 上升趋势达到了 0.01 的极显 著水平。整个生育期次之, 也达到了显著 水平。拔节后极端高温频率增加趋势不显
$4 \mathrm{c}$ 可知, 在全生育期内汝州地区最高, 达 到了 $4.0 \%-5.1 \%$, 以南阳、新乡及东部杞县、 商丘地区频率最低, 仅为 $1.8 \%-2.5 \%$ 。

总体看来, 以汝州、驻马店等地区发 生高温灾害频率最高, 拔节前灾害发生频
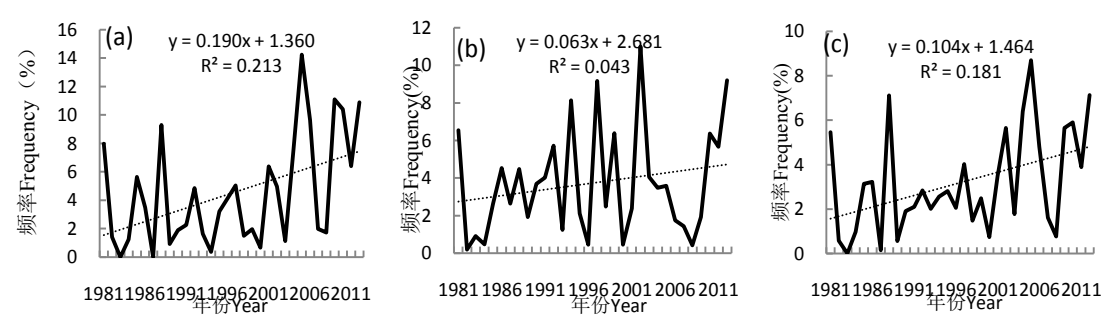

图 3. 1981-2012 年河南省极端高温频率随时间变化图 (a. 拔节前; b. 拔节后; c. 全生育期)

著。拔节前发生频率近 30 年的平均值为 $4.5 \%$, 拔节后为 $3.8 \%$, 全生育期为 $3.2 \%$ 。 可以看出, 夏玉米生育期内拔节前遭受极 端高温灾害较频繁, 且在气候变暖背景下 将变得更频繁。

由图 4a 可以看出拔节前河南省中北部 地区极端高温灾害发生频率较高, 除新乡 小部分地区较低外, 其余地区均达到 $5.1 \%$ 以上, 汝州地区最高, 达到了 $7.2 \%$ 以上。 由图 $4 \mathrm{~b}$ 可知, 拔节后南部驻马店地区发生 频率最高, 达到了近 7.2\%, 其余地区大体 上呈现出自南向北依次减小的趋势。由图
率较拔节后要高, 全生育期频率最低, 但 因为受拔节前生育期日数少于拔节后的影 响, 拔节后实际极端高温日数要比拔节前 更多。

（2）极端高温事件发生强度时空分布 由图 5 可以看出夏玉米拔节前极端高 温灾害发生强度明显大于拔节后, 并都具 有较大的波动性, 但拔节前有不断增大的 趋势, 斜率约为 0.02 , 且增大趋势达到 0.01 极显著水平。拔节后强度在 1986 年达 到极大值 $0.6^{\circ} \mathrm{C}$, 并在 $1990-2000$ 年间形成 较宽的波谷, 且都小于 $0.2^{\circ} \mathrm{C}$, 近 30 年大

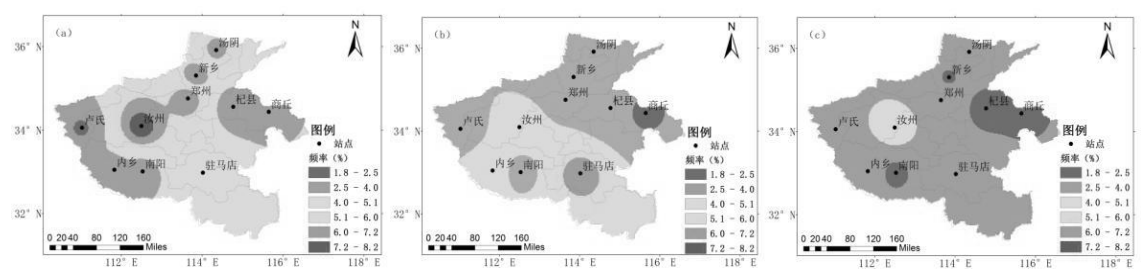

图 4.1981-2012 年河南省极端高温频率空间分布图（a. 拔节前; b. 拔节后; c. 全生育期）
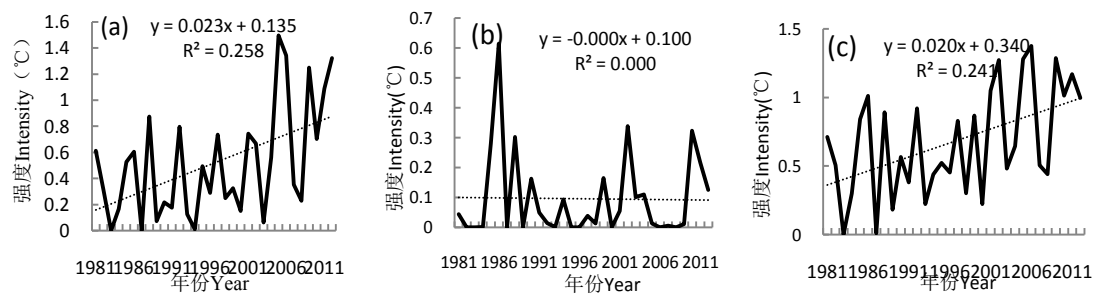

图 5. 1981-2012 年河南省极端高温强度随时间变化图 (a. 拔节前; b. 拔节后; c. 全生育期) 
体保持平稳, 无明显变化趋势, 年际波动 大。另外, 全生育期的极端高温强度也在 不断增强, 斜率约为 0.02 , 达到 0.01 极显 著水平。总体来说, 夏玉米极端高温灾害 强度有随时间不断增强的趋向, 特别是在 拔节前。

如图 6a 所示, 河南省夏玉米拔节前极 端高温灾害发生强度空间分布情况大体为 由南向北递增, 南部地区为最小值, 仅为 $0.3^{\circ} \mathrm{C}-0.5^{\circ} \mathrm{C}$; 汤阴地区达到最大值, 平均 每年约为 $0.9^{\circ} \mathrm{C}-1.1^{\circ} \mathrm{C}$ 。如图 $6 b$ 所示, 拔 节后全区极端高温强度较低, 东部杞县、 商丘地区强度最低, 仅为 $0.02^{\circ} \mathrm{C}-0.05^{\circ} \mathrm{C}$; 中西部郑州、内乡地区发生强度较高, 约 为 $0.1^{\circ} \mathrm{C}-0.3^{\circ} \mathrm{C}$ 左右。如图 $6 \mathrm{c}$ 所示, 在全 生育期内中北部汤阴、郑州地区发生强度 较高, 为 $0.9^{\circ} \mathrm{C}-1.1^{\circ} \mathrm{C}$ 左右; 杞县、卢氏地 区强度较低, 仅为 $0.3^{\circ} \mathrm{C}-0.5^{\circ} \mathrm{C}$ 左右, 但其
极端高温灾害的频率、强度与玉米产量关 系的相关性都是最大的, 分别为 0.416 和 0.475 , 并且达到了 0.01 极显著水平。全 生育期阶段的灾害发生频率、强度也都与 减产率达到 0.05 的显著相关水平。拔节前 极端高温频率和强度与减产率相关性并不 显著。

表明夏玉米产量受拔节后的极端高温 灾害的影响最大, 该阶段一旦发生极端高 温灾害将会带来产量损失, 是夏玉米受极 端高温影响的敏感时期。

\section{4. 结果与分析}

通过积温一产量模型方法确定河南省夏 玉米拔节前、后及整个生育期的极端高温 阈值分别为 $37.19^{\circ} \mathrm{C}, 35.52^{\circ} \mathrm{C}, 36.74^{\circ} \mathrm{C}$ 。 拔节后阈值明显小于拔节前和整个生育期,

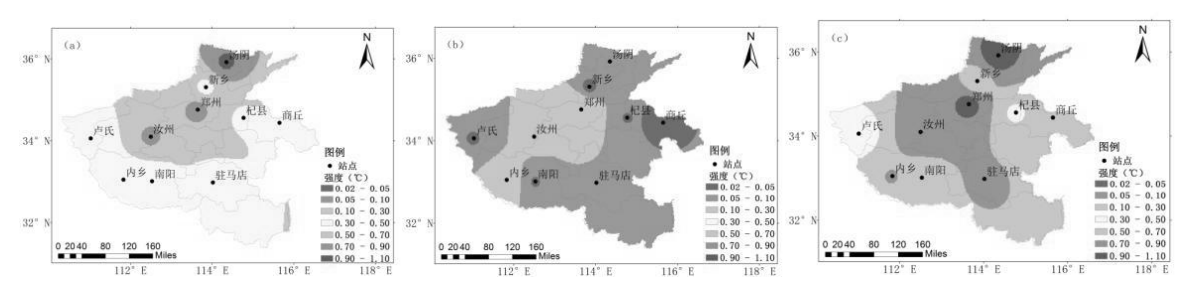

图 6. 1981-2012 年河南省极端高温强度空间分布图 （a. 拔节前； b. 拔节后； c. 全生育期）

余大片地区强度均在 $0.5^{\circ} \mathrm{C}-0.9^{\circ} \mathrm{C}$ 之间。

总体看来，极端高温强度拔节前较拔 节后高且随时间有显著增加趋势，整个生 育期情况与拔节前相似。

\section{3 极端高温对夏玉米产量的影响}

将河南省夏玉米历年平均减产率分别
说明夏玉米拔节后对于极端高温反应更敏 感。河南省夏玉米生育期极端高温无论发 生频率还是强度都有随时间增加的趋势, 其中拔节前增加最为明显, 整个生育期次 之, 拔节后不甚明显。但通过对极端高温 与减产率进行相关分析, 拔节后发生极端 高温与减产率最为相关, 会明显带来产量

表 1 历年减产率与极端高温频率、强度相关性分析

\begin{tabular}{|c|c|c|c|c|c|c|}
\hline & \multicolumn{2}{|c|}{ 拔节前 } & \multicolumn{2}{|c|}{ 拔节后 } & \multicolumn{2}{|c|}{ 整个生育期 } \\
\hline & $P$ & Q & $P$ & Q & $P$ & Q \\
\hline Pearson 相关性 & 0.204 & 0.208 & $0.416^{* *}$ & $0.475^{* *}$ & $0.314^{*}$ & $0.337^{*}$ \\
\hline
\end{tabular}

与拔节前、后以及全生育期阶段的极端高 温发生频率和强度进行 Pearson 相关分析 后得到下表。由表 1 可知, 夏玉米拔节后
损失, 是夏玉米生产的关键时期。虽然极 端高温发生有变严重的趋势但主要发生在 拔节前对产量影响有限。 


\section{Acknowledgements}

This study is supported by the National Natural Science Foundation of China under Grant No. 41501553, the Natural Science Foundation of Jiangsu under Grant No. BK20150898.

\section{致谢}

本研究得到了国家自然科学基金项目 (41501553)、江苏省自然科学基金项目 (BK20150898) 的资助。

\section{参考文献}

[1] 孙建奇, 王会军, 袁薇. 我国极端高温 事件的年代际变化及其与大气环流的 联系, 气候与环境研究, 16(2): 199208, 2011.

[2] IPCC. Climate Change 2007, the Scientific Basis. Houghton J T, Ding Y, Griggs D J, et at. Eds. Cambridge, United Kingdom and New York, NY, USA: Cambridge University Press, 2007.

[3] 崔哲洙, 蔡文香, 卢万合. 我国极端高 温研究述评, 安徽农业科学, (4): 227228, 2016.
[4] J. Xiao, Z. Huo, D. Huang, et al., Meteorological grading indexes of watersaving irrigation for corn. Journal of Risk Analysis and Crisis Response, 3-2:95-102, 2013.

[5] X. Zhang, G. Hegerl, F. W. Zwiers, et al., Avoiding In homogeneity in PercentileBased Indices of Temperature Extremes, Journal of Climate, 18(11):1641-1651, 2005.

[6] 黄丹青, 钱永甫, 我国极端温度事件 的定义和趋势分析, 中山大学学报(自 然科学版), 47(3):112-116, 2008.

[7] 冯春梅, 郭东, 冯爱国, 不同温度对 玉米产量的影响, 现代农业, (6):48-49, 2014.

[8] W. Schlenker, M. J. Roberts, Nonlinear temperature effects indicate severe damages to U.S. crop yields under climate change, Proceedings of the National Academy of Sciences of the United States of America, 106 (37): 15594, 2009.

[9] 张琪, 唐婕, 冯一淳, 等, 基于积温 产量模型确定山东夏玉米拔节前后的 极端高温阈值, 中国农业气象, 38(12):795-800, 2017. 